\title{
Benefits and Challenges of Mobile Learning Implementation: Story of Developing Nations
}

\author{
Nana Yaw Asabere \\ School of Applied Sciences and Arts \\ Computer Science Department \\ Accra Polytechnic, Accra, Ghana
}

\begin{abstract}
Mobile learning (m-learning) is a field that involves the use of mobile computing and wireless technology to enable learning occur anytime, anyplace and anywhere. The implementation strategies of mobile learning are very important for every nation due to the advantages that come with it, e.g. ease of access to education and enhanced interaction between instructors and learners. However, a lot of challenges come with mobile learning implementation, especially with respect to developing nations. This paper highlights on some mobile learning implementation challenges with a focus on Ghana, Africa and developing nations. Furthermore, the paper describes and summarizes how best to strategically overcome the enumerated challenges.
\end{abstract}

\section{General Terms}

Africa, Benefits, Challenges, Developing Nations

\section{Keywords}

Cloud Computing, Ghana, Implementation, Mobile Learning

\section{INTRODUCTION}

Mobile learning implementation requires the connection of mobile devices (e.g. smartphones, PDAs and tablet/laptop computers) to a wireless network through a deployed network platform or model [1][2]. The connection of the mobile devices in the mobile learning system should have an interactive facility or online program interface where both instructors and students can log on to participate in the mobile learning process.

Choosing the right network platform for mobile learning in your institution is important. One option is desktop computing using Client-Server architecture in which a Server application provides services to Clients. Another option increasing in popularity is a cloud computing approach [3]. Other implementation issues such as website and software development within the mobile learning system have to also be taken into consideration for effective mobile learning implementation to take place. Most developing nations need to implement mobile learning due to quite a number of reasons, some of which are listed below:

- Disparity between existing academic facilities and physical infrastructure versus the increasing number of students admitted into educational institutions.

- Limited time and place opportunities for workers. Other modes of education require students to be in the classroom or on site, which is most of the time difficult for employees as a result of their working schedules.
- Some public institutions in developing countries are being originally developed as places for both study and residence because of their national character and model adopted.

The advantages of mobile learning in education are accompanied with challenges for implementation. This paper presents a discussion of both the benefits and disadvantages of mobile learning. With reference to Ghana, the main focus of this paper is to examine major mobile learning implementation challenges of developing nations.

The rest of the paper is organized as follows: the subsections of section 1 discusses the benefits and disadvantages of mobile learning respectively. Section 2 elaborates on mobile learning implementation strategies and challenges. Section 3 summarizes the challenges enumerated in section 2 . The paper is finally concluded in section 4 .

\subsection{Benefits of Mobile Learning}

The proliferation of portable computing and mobile/ communicating devices, which are connected to wireless networks, facilitate mobility and mobile learning. Mobility allows teaching and learning to go beyond the traditional classroom, this provides a wide range of opportunities [4]. In addition, one of the principal advantages of using mobile devices for training delivery is the availability of security. Mobile devices are tightly integrated within the corporate network of a server and many of the technical and security hurdles are already handled by existing application infrastructures, for example, e-mailing activities.

Some advantages and benefits of mobile learning include [4]:

- Mobile learning can occur at anyplace and anytime, and learning content can be accessed anywhere.

- A mobile learning process is not limited to one particular place.

- Mobile learning enhances interaction between instructors and learners/students.

- Mobile learning is a great opportunity for students and instructors to continue to learn while on the move.

- Students in mobile learning practice and undergo selfcentered learning with focus.

- Mobile learning is a great opportunity for just in time training or review of content.

- Mobile learning facilitates collaboration among students and instructors through both asynchronous and synchronous communication techniques. 


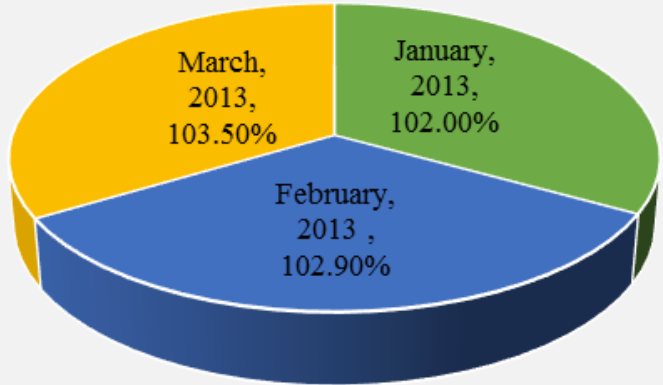

Fig 1: Mobile Telecom Voice Penetration Rates in Ghana as at January-March, 2013

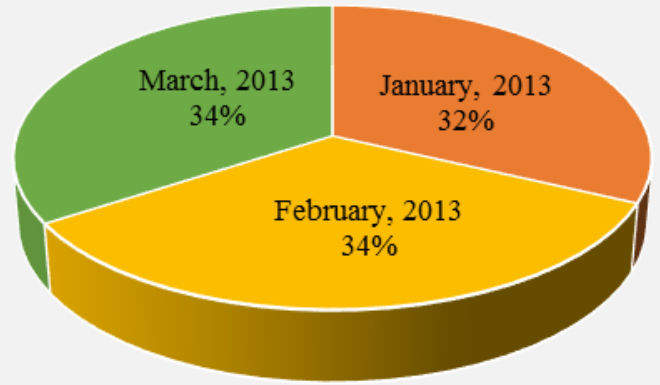

Fig 2: Mobile Telecom Data Penetration Rates in Ghana as at January-March, 2013

\subsection{Disadvantages of Mobile Learning}

Given the advancements in mobile technologies, and the personal nature of mobile devices, the establishment of a usable and accessible mobile learning system needs to be inclusive for all users. For example, individuals who are either physically impaired or disabled may find it difficult to integrate themselves within mainstream mobile education. However, ongoing research has shown that the incorporation of technologies such as the accelerometers and voice recognition systems, now standard within many modern mobile devices, provides an opportunity to develop new inclusive rather than exclusive mobile learning applications [1][4][5]. Furthermore, mobile learning is accompanied with a lot of pedagogical issues which may have negative impacts on some instructors and learners alike. Notable disadvantages of mobile learning include [4]:

- Mobile learning may give opportunities for students to cheat if there is no monitoring system in place to check cheating.

- Mobile learning can also give technically savvy students an advantage in terms of system and device usage over non-technically inclined students, such as arts students.

- Mobile learning can create an isolation or a feeling of being out-of-the-loop for both instructors and students who may not always have mobile connectivity.

- Depending on the network resources and platform, some contents in mobile learning may be rendered outdated because of rapid upgrades from one session to the next.

- Mobile learning may also require an additional learning curve for non-technical faculty and students which might introduce a burden in adoption.

- Mobile learning cannot augment practical hands-on lessons, such as laboratory experiments for chemistry students.

\section{MOBILE LEARNING IMPLEMENTATION STRATEGIES AND CHALLENGES}

\subsection{Network Infrastructure}

In most developing nations such as Ghana and Kenya, institutions were built without provision for Internet and Local Area Network (LAN) wiring [6]. To date, many buildings are being erected without these facilities. The most common solution today is to either cut into walls and floors or to use trunks to lay cables for LANs external to the building sites or campuses, which acts to destroy the aesthetics and characters of many areas in African cities/towns. The telecommunication companies in Africa don't seem to plan ahead in terms of laying cables that can be used in the future to carry both voice and data. For example, voice communication activities in many companies as well as educational institutions in Ghana, are still done using dual copper cables through both metropolitan area telephones and local telephones. This makes it even harder when a local area network has to be put in place for some institutions. Furthermore, in some cases, additional nodes have to be added to LANs, existing trunks and cables have to be taken out to lay new ones. Today, in some African countries such as Ghana, citizens live in a society where there is so much uncertainty about internal processes of organizations: a person can be moved from one office to another quite frequently and sometimes even without ample notice [6]. This frequent moving of personnel often requires wiring of new offices or buildings, and sometimes this work is accompanied by the movement of workstations and shared network equipments.

Many educational institutions in Ghana and some developing nations lose valuable productive time during these haphazard movement processes. The absence of the planning of underground ducts for most towns, campuses and compounds introduces another serious challenge. Until very recently, most building infrastructure development designs and site plans of African countries such as Ghana, Togo, Benin and Ivory Coast did not make room for ducts necessary to lay telecommunication and other cables. Where some of these ducts exist, there has been so much modification that the documentation of the underground cables is inaccurate or unreliable. Using these ducts usually requires major digging, not to mention the possibility of accidental damage [6].

Wireless LANs (WLANs) which are more expensive to install and implement usually help developing nations do away with the situations and problems listed above and place them in the better position to adopt and change more easily. A positive offshoot of WLANs with recommended standards is the provision of mobile learning. If put in place, WLANs used with wireless Internet devices such as laptops could help transform every lecture hall into an m-learning/e-learning 
center. This provides some impetus toward mobile learning practices. Mobile and cellular phones are becoming very popular and ubiquitous. Mobile phones are prevailing in all ages, income levels and social groups, which subsequently enhances the possibility of mobile learning adoption. In Ghana, statistics show that mobile phone/device penetration is on the increase. Between January-March 2013, the National Communication Authority (NCA) [7][8] released penetration rates and subscription trends of mobile telecom voice and data in Ghana. These are respectively depicted in Figures 1 and 2 as well as Tables 1 and 2. These statistics show that in Ghana, current mobile voice and data subscriptions as well as penetrations are quite high and improve monthly most of the time. With respect to voice and data usage of mobile phones/devices, such statistics and scenarios have paved the way for mobile learning in Ghana.

Table 1. Mobile Telecom Voice Subscription Trends in Ghana as at January-March, 2013

\begin{tabular}{|cccc|}
$\begin{array}{c}\text { MOBILE } \\
\text { VOICE } \\
\text { OPERATORS } \\
\text { EXPRESSO }\end{array}$ & $\begin{array}{c}\text { January, } \\
\mathbf{2 0 1 3}\end{array}$ & $\begin{array}{c}\text { February, } \\
\mathbf{2 0 1 3}\end{array}$ & $\begin{array}{c}\text { March, } \\
\mathbf{2 0 1 3}\end{array}$ \\
\hline $\begin{array}{c}\text { MILLICOM } \\
\text { (TIGO) }\end{array}$ & $3,669,472$ & $3,712,082$ & $3,676,457$ \\
\hline $\begin{array}{c}\text { SCANCOM } \\
\text { (MTN) }\end{array}$ & $11,857,772$ & $11,941,887$ & $12,024,068$ \\
\hline $\begin{array}{c}\text { VODAFONE } \\
\text { MOBILE }\end{array}$ & $5,423,932$ & $5,551,139$ & $5,609,122$ \\
\hline AIR TEL & $3,273,048$ & $3,341,715$ & $3,384,749$ \\
\hline $\begin{array}{c}\text { GLO } \\
\text { MOBILE }\end{array}$ & $1,649,767$ & $1,614,117$ & $1,607,907$ \\
\hline TOTAL & $\mathbf{2 6 , 0 8 6 , 7 9 5}$ & $\mathbf{2 6 , 3 2 4 , 7 0 2}$ & $\mathbf{2 6 , 4 6 4 , 9 6 4}$ \\
\hline $\begin{array}{c}\text { MONTH } \\
\text { OVER } \\
\text { MONTH }\end{array}$ & & $\mathbf{0 . 9 0 \%}$ & $\mathbf{0 . 5 0 \%}$ \\
GROWTH & & & \\
\hline
\end{tabular}

Table 2. Mobile Telecom Data Subscription Trends in Ghana as at January-March, 2013

\begin{tabular}{|cccc|}
\hline $\begin{array}{c}\text { MOBILE } \\
\text { DATA } \\
\text { OPERATORS }\end{array}$ & $\begin{array}{c}\text { January, } \\
\mathbf{2 0 1 3}\end{array}$ & $\begin{array}{c}\text { February, } \\
\mathbf{2 0 1 3}\end{array}$ & $\begin{array}{c}\text { March, } \\
\mathbf{2 0 1 3}\end{array}$ \\
\hline $\begin{array}{c}\text { EXPRESSO } \\
\text { MILLICOM } \\
\text { (TIGO) }\end{array}$ & $1,220,270$ & 49,720 & 49,270 \\
\hline $\begin{array}{c}\text { SCANCOM } \\
\text { (MTN) }\end{array}$ & $5,614,411$ & $1,251,190$ & $1,288,496$ \\
\hline $\begin{array}{c}\text { VODAFONE } \\
\text { MOBILE }\end{array}$ & 511,298 & 523,938 & 590,567 \\
\hline AIR TEL & 484,374 & 811,866 & 867,386 \\
\hline $\begin{array}{c}\text { GLO } \\
\text { MOBILE }\end{array}$ & 449,010 & 420,479 & 280,077 \\
\hline TOTAL & $\mathbf{8 , 3 2 8 , 9 2 0}$ & $\mathbf{8 , 8 1 6 , 6 1 1}$ & $\mathbf{8 , 8 9 5 , 4 3 0}$ \\
\hline $\begin{array}{c}\text { MONTH } \\
\text { OVER } \\
\text { MONTH }\end{array}$ & & $\mathbf{5 . 8 0 \%}$ & $\mathbf{0 . 9 0 \%}$ \\
GROWTH & & & \\
\hline
\end{tabular}

\subsection{Cognitive Challenges}

In addition to the technology implementation challenges, such as the convergence of wireless infrastructure with handheld devices, cost issues, the smoother delivery of learning content and the innovations in content creation, there are also cognitive challenges of mobile learning, which are elaborated below:

\subsubsection{Realizing and Adjusting to Mobile Learning Environments}

The challenge of adjustable learning is core to mobile learning. The critical issue is adapting to the change from traditional learning. In mobile learning, the key question is how people create learning contexts for learners through their interactions with mobile devices. There are differences between context of mobile learning and traditional classroom contexts.

Secondly, another cognitive challenge for mobile learning implementation is how to manage and evaluate the assessment of the learning processes and outcomes. In the traditional learning mode of education, there are many well-established and accepted methods for the assessment of learning activities, such as essay writing, multiple choice tests, openbook exams, and normal written examinations [9]. In contrast, mobile learning may be personally initiated and structured, such that it is not possible to thoroughly and actually determine in advance where the learning may occur, nor how the learning progresses and what the final outcome of the learning process might be. It may also be difficult to track the progress of learning if it occurs across multiple/different settings using a variety of devices.

\subsubsection{Assessment of Mobile Devices and Equipments}

Insufficient text and content display of mobile devices to support mobile learning is also another cognitive challenge. The learning procedure, context and usability factors such as display size and battery life affect user practices. This is equally important for features of smart phones and tablets.

\section{SUMMARY OF ENUMERATED CHALLENGES}

Developing nations such as Ghana should also consider a positive offshoot of deploying cloud computing as a network model or platform instead of WLAN through desktop computing. Cloud Computing is a new technology and has various advantages which are adoptable in this present scenario and will eliminate so many mobile learning implementation challenges. When cloud computing is used as a network resource and platform for mobile learning, it is more advantageous as compared to desktop computing network resources in terms of cost, flexibility and accessibility, just to name a few.

The biggest problem for Ghana and other developing nations is that, the organizations trying to offer technology for mobile learning are in their tight budgets. Due to the high cost of deploying mobile learning technologies, most educational institutions in Ghana and other developing nations cannot implement mobile learning. The advantage of low cost in cloud computing can help to overcome this handicap situation. The advantages of mobile learning have been acknowledged, however, substantial investments for mobile learning implementation remains a hard nut to crack. 


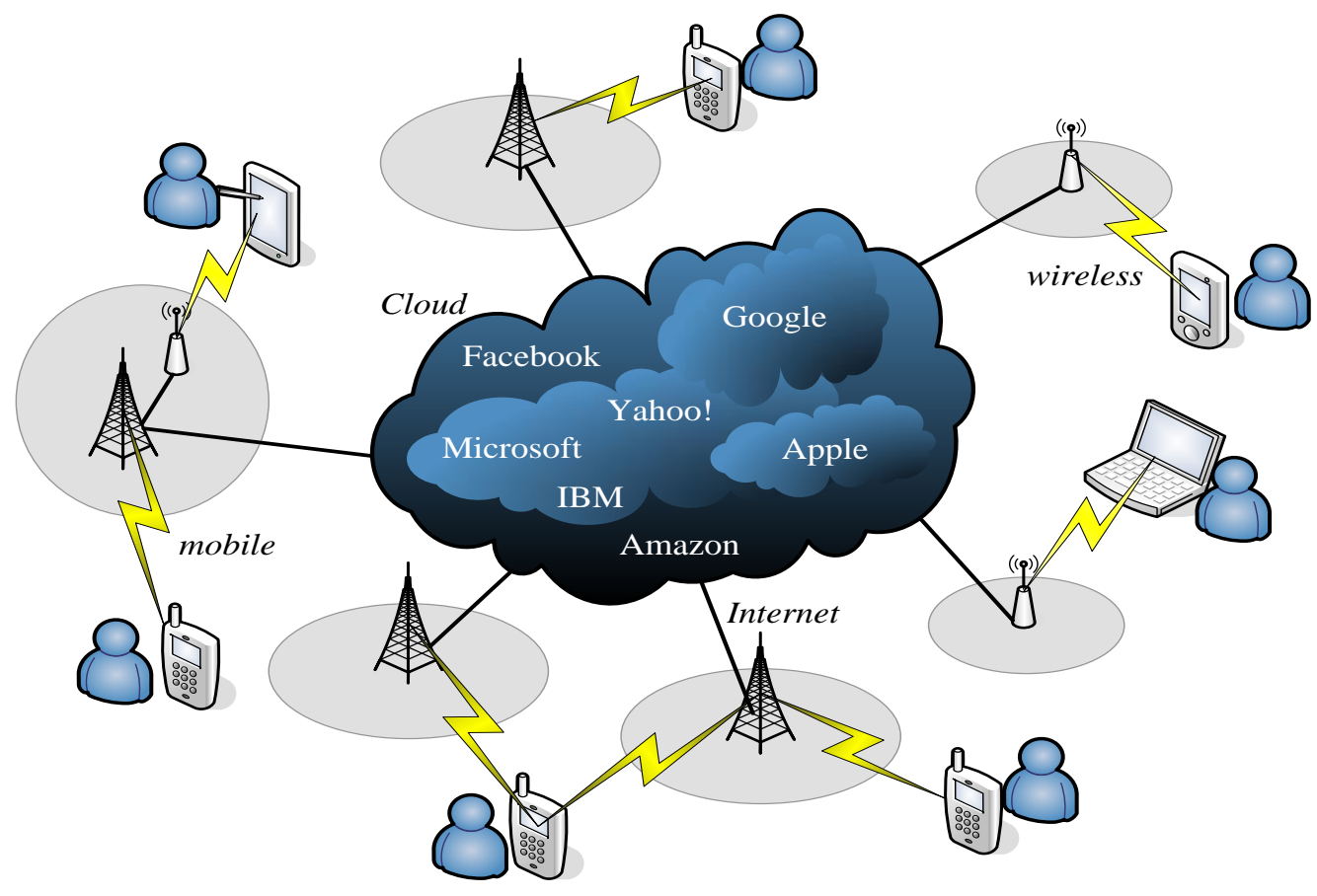

Fig. 3: Mobile Cloud Computing Platform

On one hand, educational establishments cannot afford the necessary resources and equipments and on the other hand institutions that have the equipments cannot use them to their full potential because of service cost issues. Cloud computing will obviously introduce Hardware as a Service (HaaS) and Software as a Service (SaaS) features/characteristics which will not allow the equipments to be an enormous waste of resources.

In most developing nations, when it comes to tapping into technology, there is too much time consumed for implementation. Cloud computing drastically reduces time for implementation, which helps the organization, the government and the people in a very big and dynamic way. Shown in Figure 3 is a diagram of mobile cloud computing, which can be employed for a mobile learning system implementation.

The implementation process of mobile learning should also consider a mobile learning management system (M-LMS) which usually provides mobile browser access to driven applications such as recorded video/audio lectures, course website interfaces, study materials, chatting forums etc. An M-LMS is usually developed and designed using Extensible Markup Language (XML) and Java programming language technologies.

In addition, the benefits of mobile devices, demands new pedagogies, academic approaches and styles to deliver and facilitate education. If mobile learning is properly facilitated, learners should be provided with interaction activities and favorable instruction materials wherever and whenever they need it. To keep up with this changing phenomenon and to effectively facilitate mobile learning, it is essential that instructors learn and adapt to the changing environments when and where appropriate [10].

\section{CONCLUSION}

Mobile learning is the future of education in Ghana, Africa as a whole and many other developing nations, particularly for people in the deprived and sparsely populated areas. Mobile learning implementation strategies require policy makers to be informed about technology and to seek opinions from relevant stakeholders and ICT vendors. The large-scale proliferation of mobile devices among the people in Ghana as elaborated in this paper and the ubiquitous availability of data and applications through cloud computing offers remarkable opportunities to overcome the digital and economic divide. Policies and guidelines in Ghana as well as other developing nations should be put in place to direct telecommunication companies to channel their corporate social responsibility towards mainstream education by committing themselves to championing mobile learning with the rural communities as their targets.

\section{REFERENCES}

[1] D. Frohberg, C. Göth and G. Schwabe, "Mobile Learning Projects - A Critical Analysis of the State of the Art", Journal of Computer Assisted Learning, Vol. 25, Issue 4, pp. 307-331, August 2009.

[2] L. F. Motiwalla., "Mobile Learning: A Framework and Evaluation", Computers \& Education, Vol. 49, Issue 3, pp. 581-596, November 2007.

[3] M. Wang and J.W.P. Ng, "Intelligent Mobile Cloud Education", Eighth International Conference on Intelligent Environments (IE12), Guanajuato, México, , pp. 149 - 156, June 2012.

[4] J.R. Corbeil and M.E. Valdes-Corbeil, "Are You Ready for Mobile Learning", Educause Quarterly, pp. 51-58, No. 2, 2007.

[5] T.J. Mehigan. "Harnessing Accelerometer Technology for Inclusive Mobile Learning", $11^{\text {th }}$ International Conference on Human-Computer Interaction with 
Mobile Devices and Services (MobileHCI09), Bonn, Germany, September 2009.

[6] F. K. de Heer-Menlah, "An Investigation into Wireless Technology for M-Learning at GIMPA", $3^{\text {rd }}$ International Conference on ICT for Development, Education and Training (eLearning Africa), Accra, Ghana, May 2008.

[7] National Communication Authority (NCA), Ghana Mobile Telecom Voice Penetration Rates and Subscription Trends, Jan.-March 2013, Available [Online]

http://www.nca.org.gh/downloads/Telecom_Voice_Subs cription_March_2013_web_version.pdf (Accessed: 22/05/2013)
[8] National Communication Authority (NCA), Ghana Mobile Telecom Data Penetration Rates and Subscription Trends, Jan.-March 2013, Available [Online] http://www.nca.org.gh/downloads/Telecom_Data_Subscr iption_March_2013_web_version.pdf (Accessed: 22/05/2013)

[9] G. Vavoula and M. Sharples, "Meeting The Challenges in Evaluating Mobile Learning: a 3-level Evaluation Framework", International Journal of Mobile and Blended Learning, Vol. 1, No. 2, pp. 54-75, 2009.

[10] S.K. Sharma and F.L. Kitchens, "Web-Services Arcticture for M-Learning," Electronic Journal on ELearning, Vol. 2, No. 1, pp. 203-216, 2004. 